\title{
Detection of Afforestation, Reforestation and Deforestation (ARD) by Visual Photo Interpretation of High Spatial Resolution Images - A Fundamental Case Study -
}

\author{
Shuji Hori ${ }^{* 1}$, Masato Hayashi ${ }^{* 1}$, Yoshitaka Matsubara*1, \\ Yoshio Awaya $^{* 2}$ and Toshiro Iehara*2
}

\begin{abstract}
Kyoto Protocol Article 3.3 calls for the identification of land use changes to better evaluate emissions and sinks of greenhouse gases. Here we investigated the ability of high spatial resolution imagery to examine changes in afforestation, reforestation and deforestation (ARD). Initially, we checked capability of the imagery in identifying land cover types by visual interpretation. Although digital orthophotos were capable of identifying various landcovers, a panchromatic HRV (HRV-P) image wasn't able to distinguish between young forests, crop fields and grasslands due to poorer picture quality in grey levels and spatial resolution than orthophotos. The poor quality of HRV-P images caused disagreement of ground object identification with the orthophotos by approximately $20-30 \%$ in the visual interpretation. Taking into the picture quality and the error causes into consideration, we visually interpreted ARD in Kumamoto prefecture using orthophotos for the beginning of the period and HRV-P images for the end of the period. A field validation showed that user's accuracy of detecting deforestation (D) was $92 \%$, and that of detecting afforestation and reforestation (AR) was barely $50 \%$. Although it was impossible to separate land-use changes from land-cover changes perfectly by visual interpretation, detecting deforestation was very accurate. The major causes of errors were interpreting cut-overs as D, and interpreting crop fields and grasslands as forest on the HRV-P images. Annual occurrence rates for AR and D were $0.001 \%$ and $0.048 \%$ of the land area, respectively. Annual occurrence of $\mathrm{D}$ was $0.032 \%$ of the land area according to a census. The interpreted $\mathrm{D}$ area was consistent with the census information. Thus ARD detection by visual photo interpretation, which clearly shows human-induced ARD areas, is suitable for meeting the monitoring requirements of the Kyoto Protocol.

The interpretation using a Geographical Information System was better at identifying ARD areas because it used high resolution images with geographical coordinates, since the land-use change type and their locations were identifiable. We expect to be able to estimate total of land-use change areas with spatial information by decreasing the uncertainties in ARD visual interpretation and by introducing an efficient sampling method, which can estimate country-wide changes.
\end{abstract}

Keywords: visual photo interpretation, orthophoto, SPOT HRV-P image, land cover change, land use change

\section{INTRODUCTION}

A requirement of the Kyoto Protocol (UNITED NATIONS, 1998; Article 3.3) is to report the emissions and removals of greenhouse gases resulting from direct human-induced land-

\footnotetext{
${ }^{* 1}$ Japan Forest Technology Association, 6-7, Chiyodaku, Tokyo 102-0085 Japan

${ }^{* 2}$ Forestry and Forest Products Research Institute, 1, Matsunosato, Tsukuba, Ibaraki 305-8687 Japan
}

use change and forestry activities from the beginning of 1990 until the end of 2007 in terms of afforestation, reforestation and deforestation (ARD). There are, however, no obvious and localizable continuous data regarding land-use since 1990 in Japan. The World Census of Agriculture and Forestry (MAFFSSD, 2000), which is published every ten years as administrative statistical information, shows the area of forests throughout Japan. The census shows the area converted from forests into other land-uses, and this will be applicable as information regarding the area-change corresponding to the Kyoto Protocol Article 3.3 deforestation.

However, this information is merely a repetition of 
existing records of approvals for forestland development (Forestry AgENCy Conservation Division, 2005; MAFFPDS, 2005). Thus, we cannot trace locations where conversion happened after 1990, although locations of land-use changes have to be identifiable (UNFCCC, 2001). When quoting the item, which is "Area of conversion from forests to other landuses according to use" in the World Census of Agriculture and Forestry, in the report designed for the Kyoto Protocol Article 3.3 (hereafter Kyoto Protocol Report), we must establish a system that can interpret land-use changes explicitly and verifiably using geographical information that can be spatially compared (IPCC, 2003). Thus the Forestry Agency of Japan has started developing an ARD monitoring system using remote sensing data including aerial orthophotos, and prepared digital aerial orthophotos and panchromatic images of High Resolution Visible (HRV-P) on SPOT-5 (a French Earth observatory satellite).

Change detection is one of most common research topics in remote sensing. ROSENQVIST et al. (2003) pointed out the possibility of utilizing satellite remote sensing for ARD detection. Digital image analyses such as differentiation of images, classification of images obtained in different times are common approaches of change detection (MAS, 1999). Among simple change detection methods, difference of two images is most accurate, although land covers are not shown. An ARD detection method based on differences between Thematic Mapper (TM) images was developed by KAKUTA et al. (2007) and was tested in Kumamoto prefecture by HAYASHI et al. (2007). The results of ARD detection were not sufficiently accurate in those studies. The causes were analyzed by these authors and MrYASAKA et al. (2007). One of critical cause of errors is that spectra of land-covers change greatly after logging in a long period (e.g. 15 years) and there is very little difference in change of radiance values between areas with and without ARD. It may be possible to detect ARD occurrence, if ARD is analyzed year after year. However, cloudfree TM images are rarely observed in many parts of Japan (AKIYAMA and KAWAMURA, 2003). Thus it is very difficult to detect ARD occurrence using TM images, which are the most suitable base information and have been recorded since 1984 , and we decided to develop an ARD detection method by visual interpretation of high spatial resolution images.

There are some problems to be checked. For example, images show not land-use but land-cover. Quality of othophoto and HRV-P images are different, and image quality influences the accuracy of ARD detection. Therefore, evaluating a) problems caused by detecting land-cover changes instead of land-use changes, and b) influence of image quality on interpretation accuracy is important for designing the ARD detection method.

We introduce a basic idea of monitoring ARD by visual photo interpretation at first. Then we evaluate capability of high-resolution images in visual photo interpretation. Finally, we discuss the accuracy of photo-interpretation and causes of errors on a prefecture-wide scale.

\section{TEST SITE}

We chose two test sites. A $12 \mathrm{~km}$ square area was selected in Hachioji City, Tokyo to know the capability of distinguishing ground objects by visual interpretation using high spatial resolution images and to develop an ARD interpretation scheme. Kumamoto prefecture was selected as a test site for developing a nation-wide $\mathrm{ARD}$ interpretation operation. We set points at intervals of $8 \mathrm{~km}$ in Kumamoto prefecture and assigned a square of $2.5 \mathrm{~km}$ by $2.5 \mathrm{~km}$ at each point (about $588.9 \mathrm{~km}^{2}$ in total) for interpretation. This is equivalent to $8.5 \%$ of the entire area of Kumamoto prefecture, which is about $6,909.3 \mathrm{~km}^{2}$ according to the nationwide square survey by the Geographical Survey Institute reported on 1 Oct, 2004.

\section{IMAGE DATA}

Digital aerial orthophoto images (AwAYA et al., 2006), which represent land-cover at the beginning of the period (BP, the end of 1989), and HRV-P images, which represent land cover at the end of period (EP, end of 2007) are going to be used for ARD monitoring of the Kyoto Protocol Report by the Forestry Agency. The HRV-P images were originally prepared not for ARD monitoring but for conservation forest

Table 1 Images for study

\begin{tabular}{|c|c|c|c|c|c|}
\hline Area & Time & Data type & Observation Date & Pass-Row & Ground Resolution \\
\hline \multirow{3}{*}{ Hachioji, Tokyo } & At the biginning of period (BP) & Aerial ortho-photos & 2 May, 1980-18 Oct., 1989 & - & $1 \mathrm{~m}$ \\
\hline & \multirow{2}{*}{ At the end of period (EP) } & Aerial ortho-photos & Jul-Sep 2001 & - & $1 \mathrm{~m}$ \\
\hline & & Spot-5/HRV-Pan & 12 Oct., 2002 & $330-278$ & $2.5 \mathrm{~m}$ \\
\hline \multirow{7}{*}{ Kumamoto } & $\mathrm{BP}$ & Aerial ortho-photos & 20 Sep., 1984-21 Oct., 1992 & - & $1 \mathrm{~m}$ \\
\hline & \multirow{6}{*}{$\mathrm{EP}$} & \multirow{6}{*}{ Spot-5/HRV-Pan } & 6 Jul., 2004 & $314-284$ & \multirow{6}{*}{$2.5 \mathrm{~m}$} \\
\hline & & & 24 Anr 2004 & $314-285$ & \\
\hline & & & $24 \mathrm{Apr}$ & $314-286$ & \\
\hline & & & \multirow{2}{*}{5 May, 2004} & $315-284$ & \\
\hline & & & & $315-285$ & \\
\hline & & & 17 Jul., 2004 & $315-286$ & \\
\hline
\end{tabular}


management by the Forestry Agency. Although BP and EP have been determined, images were not or will not be obtained at these times. Time difference between BP or EP and obtained dates of images were or will be existed.

The orthophoto images have $1 \mathrm{~m}$ resolution and are designed to have with a root mean square error (RMSE) of less than $10 \mathrm{~m}$. HRV-P images have $2.5 \mathrm{~m}$ resolution and are geometrically corrected using $1 / 25,000$ topographic maps published by the Geographical Survey Institute; therefore, the location accuracy of HRV-P images would be $\pm 17.5 \mathrm{~m}$ with the same horizontal accuracy to the topographic maps (MLITSTIS, 2004).

Images used in this study are listed in Table 1. For the Hachioji test site, the orthophoto images promoted by the Forestry Agency were used as images for BP. A HRV-P image taken in 2002 was ortho-projected for use as an image for EP. Digital orthophoto images produced from aerial photographs taken in 2001 were also used as images of EP to evaluate quality and usefulness of the HRV-P image. In the case of Kumamoto, the orthophoto images provided by the Forestry Agency were used as the BP images, and ortho-projected HRV$\mathrm{P}$ images taken in 2004 were used as the EP images.

\section{METHODS}

Interpretation Types and Standard

There were 7 interpretation types assigned as shown in Table 2. ARD means the direct artificial land-use change between forest and other types of land use (UNFCCC, 2001). Therefore, with a view point of interpreting ARD areas, one need only interpret areas with land-use change, not including changes in land-cover such as those caused by forestry activities. In the development of the ARD interpretation method, however, we interpreted and distinguished changes both in land-use and land-cover. If we interpret only land-cover changes which would include changes by ARD, uncertainty in land-cover change detection can be evaluated. However, ARD land-use changes among land-cover changes cannot be distinguished, and error factors caused by the interpretation design cannot be analyzed. Therefore, it is necessary to interpret changes both in land-use and land cover.

We classified ARD into 6 types in the visual interpretation to distinguish land-use and land-cover changes (Table 2). As for D, changes by logging activities are categorized into 3 types based on causes such as land-use change, forestry activities or natural hazard and unknown cause. AR is typed as well as D.

We conducted field validation to evaluate the interpretation results including accuracy by focusing where or at which type of land-cover the judgment of whether land-use change or land cover change was difficult.

\section{ARD Interpretation Method}

Interpretation was carried out using a geographical information system (GIS) (TNT-mips, Microlmages Inc., USA). We compared the ortho-images from two time points visually and detected ARD (Fig. 1). At first, we displayed both the BP digital orthophoto images and the EP HRV-P images on the display with coordinates, and interpreted cover changes regarding forests. Secondly, we judged whether the change

Table 2 ARD interpretation type and object name

\begin{tabular}{|c|c|c|}
\hline ARD type & Object name & Remark \\
\hline From forest to other land-use. & $\mathrm{D}$ & $\begin{array}{l}\text { Land-use change into other than forest, such as road and slope (including } \\
\text { forest road), quarry and dam (water), golf links, ski area, farm land, } \\
\text { residential district, factory. }\end{array}$ \\
\hline $\begin{array}{l}\text { Forestry deforestation, } \\
\text { Natural hazard (typhoon, landfall, forest } \\
\text { fire). }\end{array}$ & FMD & $\begin{array}{l}\text { Areas from forest to non-forest through the deforestation like cut-over land } \\
\text { and hazard (out of the Kyoto Protocol). }\end{array}$ \\
\hline To forest from other land-use. & $\mathrm{AR}$ & $\begin{array}{l}\text { Changes from farm land or grass field to forest. It is difficult to detect the } \\
\text { existence of forestation, then we judge by the BP orthophoto images with } \\
\text { high resolution. If non-forest land-use has changed into forest cover, we adopt } \\
\text { them. }\end{array}$ \\
\hline $\begin{array}{l}\text { Forest from cut-over land by forestation etc. } \\
\text { Areas, in which once natural hazard } \\
\text { occurred, were covered with forest. }\end{array}$ & FMAR & $\begin{array}{l}\text { Cut-over areas at BP and forest at EP. Existence of forestation is not } \\
\text { considered because of the difficulty in distinguishing them from natural } \\
\text { growth. }\end{array}$ \\
\hline $\begin{array}{l}\text { Deforestation. Unknown cause whether by } \\
\text { forestry deforestation or land-use change. }\end{array}$ & $\mathrm{DQ}$ & $\begin{array}{l}\text { Cases where it is difficult to distinguish causes due to HRV-P image } \\
\text { resolution and an inadequate quality of the BP orthophoto images. }\end{array}$ \\
\hline $\begin{array}{l}\text { Forest area that was not so in the BP image. } \\
\text { Unknown whether it is caused due to } \\
\text { afforestation. }\end{array}$ & $\mathrm{ARQ}$ & $\begin{array}{l}\text { Land-use change from non-forest at BP to land-use ambiguous to forest-cover } \\
\text { at EP, such as artificially replanted slope, green of the park, green of the } \\
\text { factory, green along the river, agricultural abandoned area. }\end{array}$ \\
\hline Illegible area due to snow, cloud, noise etc. & Cloud & \\
\hline
\end{tabular}




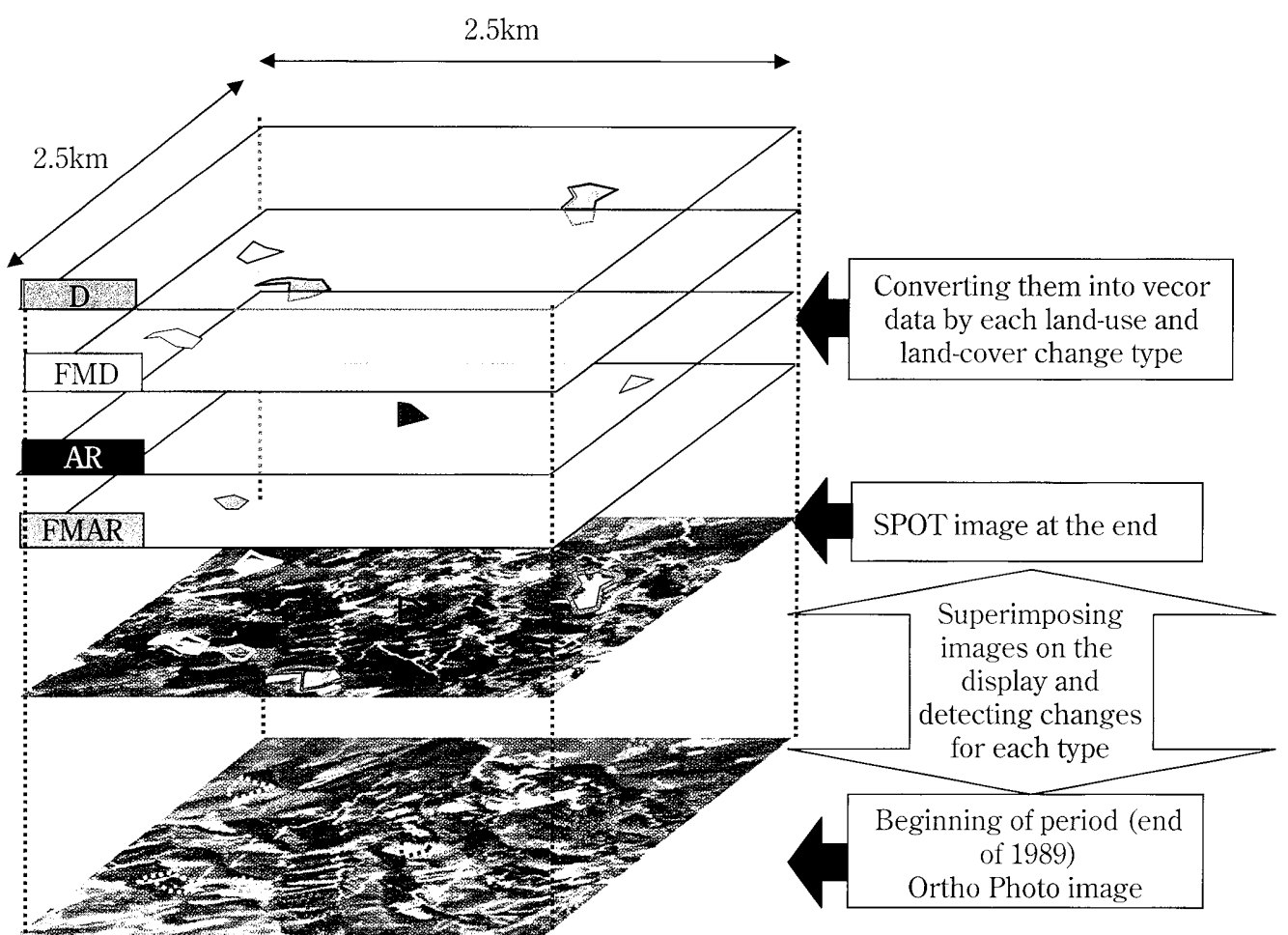

AR

Afforestation Reforestation

FMAR From logging area to reforestation

D Deforestation

FMD Logging area, young afforestation area
With land-use change

Without land-use change

With land-use change

Without land-use change

Fig. 1 Outline of visual interpretation method using GIS software

was relevant to $\mathrm{ARD}$, and the area with change was digitized as a polygon according to the interpretation types in Table 2 .

\section{ANALYSIS}

Image quality check and accuracy assessment are mandatory for the following reasons.

1) Images used for ARD detection are black and white and are quantified to 8 bit grey levels. Ground resolution of aerial orthophoto and HRV-P images are $1 \mathrm{~m}$ and $2.5 \mathrm{~m}$ respectively. It means that images cannot show colors, small differences in brightness and small objects in detail. Therefore, there is a limit to how well ground objects can be correctly identified and it is necessary to clarify the limitation in interpretation to reduce errors caused by image quality.

2) Although ARD is defined as land-use change in the Kyoto Protocol, aerial and satellite images record land-cover information. This means that image interpretation would not show all of land-use changes. For example, if forest under forest management is converted to an urban park, land-use of the forest is changed from managed forest for forestry to nonmanaged forest. The change does not appear in images. Therefore, we have to make clear that what kind of land-use changes are detectable, and what kind of discrepancies are present between actual and interpreted ARD areas.

Based on the evaluation, we shall develop ARD interpretation types to make accurate ARD detection possible.

Evaluation of Image Quality

Before interpreting the data for detecting ARD, geometric accuracy and picture quality were validated for the images in Table 1. Verification of the geometric accuracy of the BP orthophotos in Kumamoto was conducted using road data in Digital Map 25000 published by the Geographical Survey Institute in 2003 in seven cities in Kumamoto prefecture. As for 
picture quality, histograms and visual identification of ground objects were checked. Histograms of both images were counted in the same area and compared with each other regarding the gray level range.

Since stereoscopic interpretation using stereo pair photos has not been available in the interpretation of ortho-images, recognition of ground objects (e.g. trees) becomes difficult, because no vertical information is available. Stereoscopic interpretation is the ideal and best method to identify ground objects using high spatial resolution images. Therefore identification of different stages of forest and other land-covers by visual interpretation was examined using stereo pair aerial photos, the orthophoto and HRV-P images. The results were summarized to know the capability of identifying ground objects, using the stereo pairs as a standard.

Comparison of Interpretation Results between Orthophoto and HRV-P Images

Since picture quality of the HRV-P images was poorer than that of the digital orthophoto images, we compared ARD detection results in Hachioji using the orthophoto and HRV-P images as the EP images to understand the deterioration of accuracy and problems by using the HRV-P images instead of using the orthophoto images.

Discrepancy in interpretation results by the same interpreter using the orthophoto and HRV-P images was assessed in the Hachioji test area, which covered an area of $12 \mathrm{~km}$ by $12 \mathrm{~km}$. Differences in changed areas in forest and non-forest, which included ARD in terms of land-use changes and also land-cover changes, were evaluated. Polygons covering the changed areas were converted into $30 \mathrm{~m}$ raster pixels using image processing software (Imagine 8.7 by Leica Geosystems GIS and Mapping LLC., USA) in order to measure area. Areas with different interpretation results were classified according to causes, and all areas with difference by each cause were verified both on the images and in the field. Accuracy of the interpretation using the EP HRV-P image was evaluated using producer's accuracy, user's accuracy and the Kappa coefficient (CONGALTON, 1991) to the interpretation results of the EP orthophoto images, which were assumed to be true and used as the truth. Producer's accuracy and user's accuracy show the correspondence between detection results and ground truth. Producer's accuracy is calculated as the ratio of the corresponding area to the area of truth data, and user's accuracy is calculated as the ratio of the corresponding area to the area of detection results. The Kappa coefficient explains the correspondence between the classification result and the ground truth map except coincidence of errors in both producer's accuracy and user's accuracy.

\section{ARD Detection in Prefecture Scale}

ARD patterns are expected to vary regionally and to result in misinterpretation. Therefore, we conducted a test of ARD detection in the Kumamoto area using the HRV-P images to check for problems that might occur on an operational scale. The area for visual interpretation covers about $8.5 \%$ of the prefecture. Since frequency of ARD was unknown, we interpreted such large area to check appropriate sampling rate. Areas where the EP HRV-P images were obscured due to such as cloud coverage were excluded from the ARD interpretation. Error factors were analyzed according to the results of field verification in the case of Kumamoto.

Comparison with Administrative Information Regarding LandUse Change

Interpretation results were compared with the data of the conversion square measures from forest to other land uses in the World Census of Agriculture and Forestry (MAFFSSD, 2000). ARD areas interpreted by the digital orthophoto images and digitized sub-compartment boundaries in non-national forest area under forest management were compared with each other in some areas to understand problems that might occur in using administrative information in ARD detection.

\section{RESULTS AND DISCUSSION}

\section{ARD Interpretation Method}

The advantage of the method, which identifies ARD using ortho-images on GIS, is that it makes it possible to display the interpretation results as geographical information in real time. The interpretation results, in the form of polygons, were compared visually with the BP and EP images simultaneously on the display, and images gave information of land-cover type (Fig. 1). The method showed geographical location of each ARD area which is required to be clarified in the Marrakech Accords (UNFCCC, 2001). The method enables us to measure the area of ARD to stratify ARD areas by size for the purpose of e.g. eliminating areas under 0.3 ha. Moreover, we can easily compare the interpretation results with other geographic information.

\section{Evaluation of Image Quality}

The horizontal location accuracy was $3.0 \mathrm{~m}$ in RMSE for the case of aerial orthophoto images (Fig. 2a). The aerial orthophoto images were produced with higher accuracy than the original specification (AWAYA et al., 2006), which aimed at a precision of $10 \mathrm{~m}$ in RMSE. As for the EP HRV-P images, the RMSE was $6.8 \mathrm{~m}$, and the images were deflected to the west (Fig. 2b). Furthermore, horizontal positional difference was up to $20 \mathrm{~m}$ between the BP orthophoto and EP HRV-P images in Kumamoto. Geometric error of the orthophoto images was smaller than that of the HRV-P images. For this reason, if registration of these two images was not sufficiently accurate, 

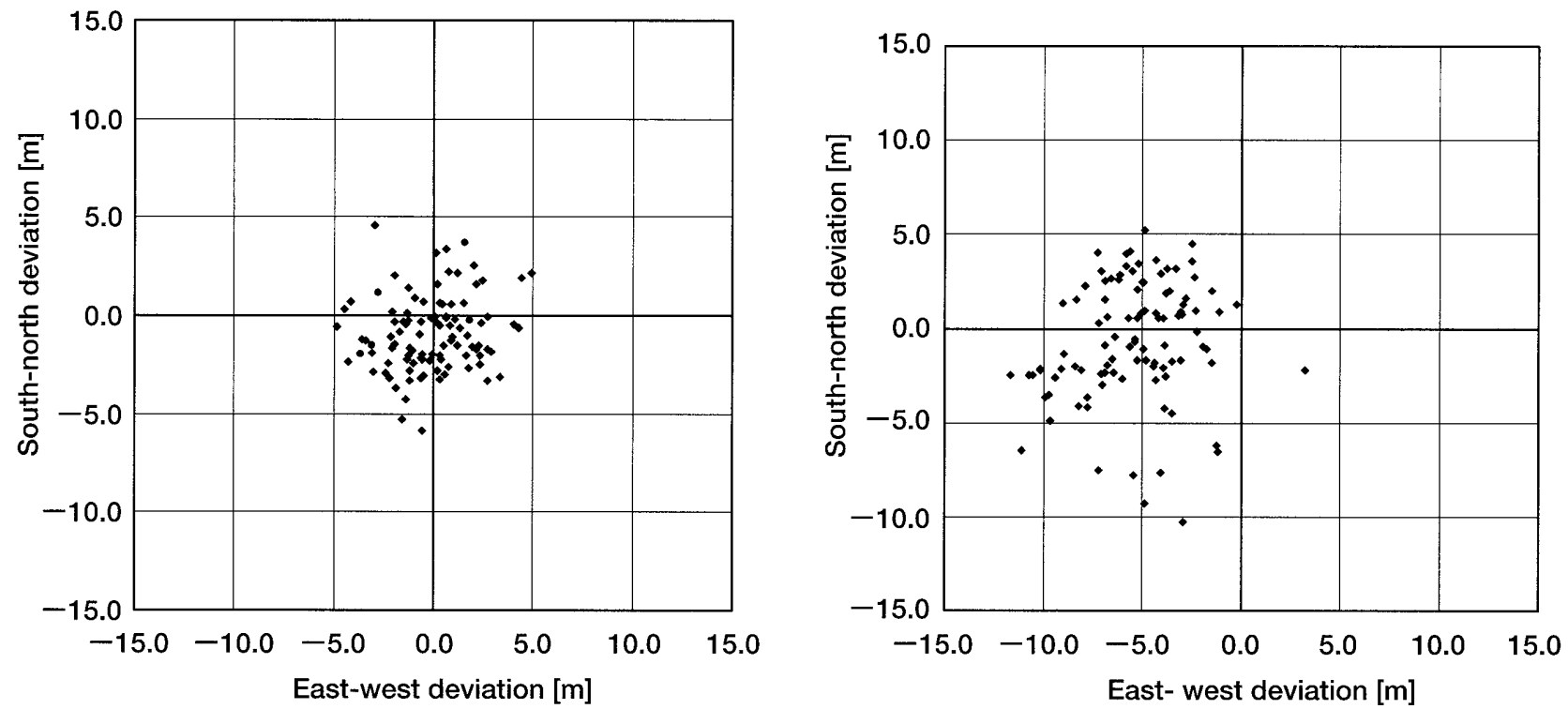

Fig. 2 Geometric accuracy of images

a) shows the accuracy of digital or thophoto images with RMSE of $3.0 \mathrm{~m}(\mathrm{~N}=100)$.

b) shows the accuracy of HRV-P images with RMSE of $6.8 \mathrm{~m} \quad(\mathrm{~N}=100)$.
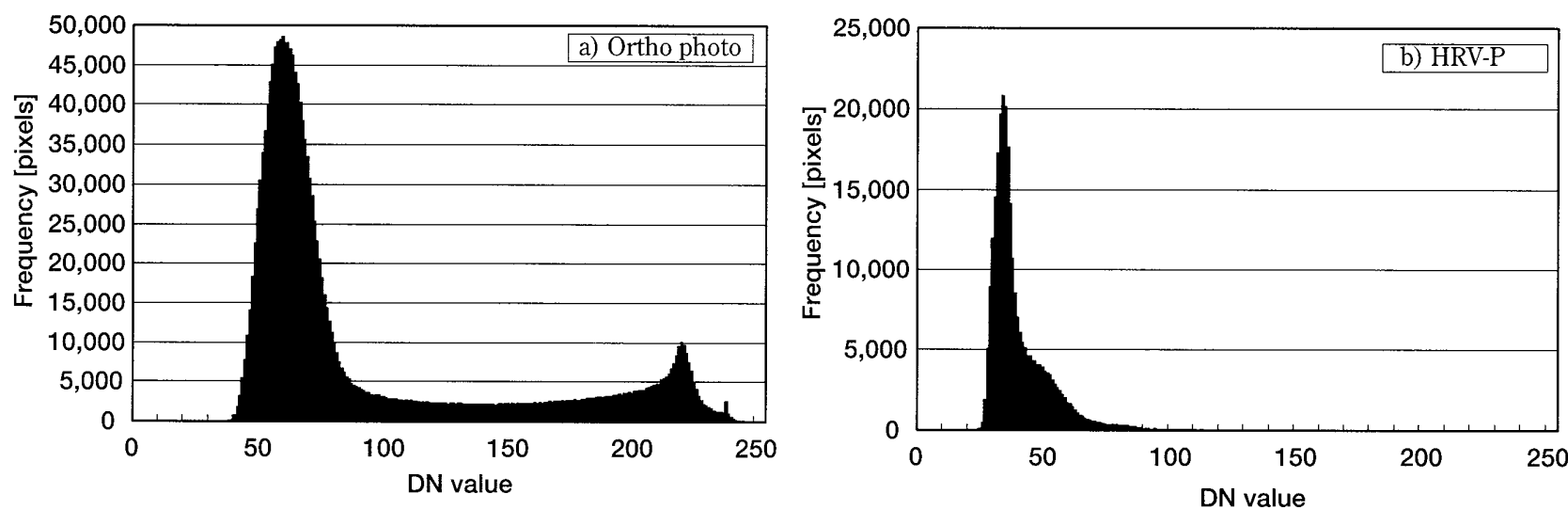

Fig. 3 Histograms of orthophoto and HRV-P images

a) the case of aerial orthophoto images and b) SPOT-5 / HRV-Pan images.

The histograms were counted by DN values in the same area.

the aerial orthophoto images were used as a standard of location and the HRV-P images were moved parallel to adjust to the orthophoto images.

As shown in Fig. 3, the EP HRV-P image were inferior to aerial photographs in terms of brightness gradient even though they, like the orthophoto images, were panchromatic with 256 gray levels. The gray level range in the HRV-P images was about half of that in the orthophoto images. Due to the much narrower gray levels of HRV-P images, ground objects would appear blurrier in the HRV-P images than in the orthophoto images.

The characteristics of visual photo interpretation are summarized in Table 3 and Fig. 4. The narrow gray level range and coarse ground resolution of HRV-P images made them more difficult to visually identify ground objects than the or thophoto images.

The ground resolution of the BP orthophoto images was $1 \mathrm{~m}$, which was inferior to the $20 \mathrm{~cm}$ resolution of black-andwhite photographs taken on a scale of $1 / 20,000$ (TSURU, 2004). However, one meter resolution is sufficient to visualize boundaries between forest and non-forest areas, and to identify most of ground objects. On the other hand, the $2.5 \mathrm{~m}$ ground resolution of HRV-P makes distinguishing forest and nonforest more difficult as described below. 


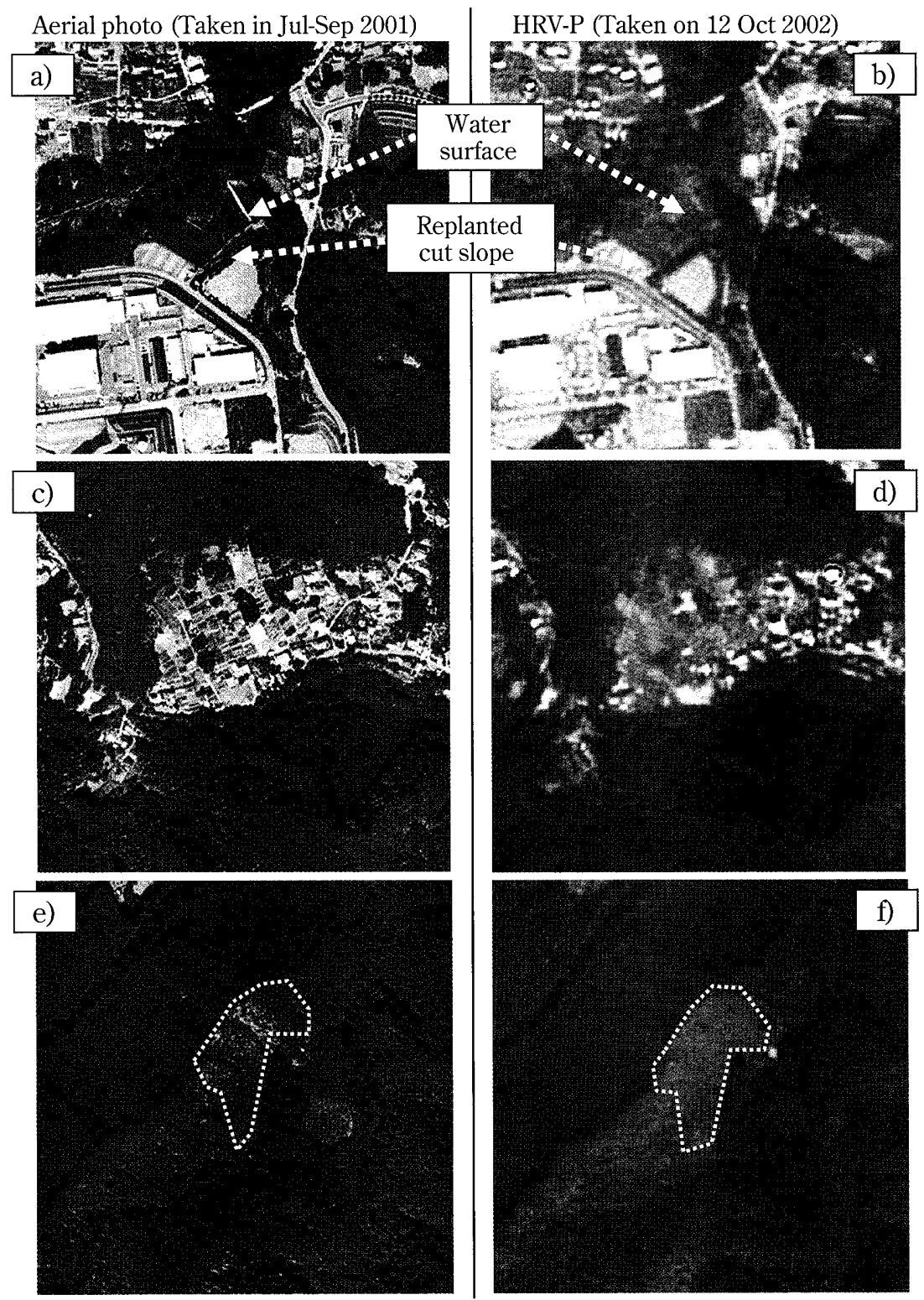

Fig. 4 Difficult cases of visual photo interpretation due to HRV-P image quality a), c) and e) are aerial orthophoto images taken in Jul-Sep 2001. b), d) and f) are HRV-P images taken on 12 Oct 2002. a) and b) are an example of difficult cases due to the mixture of water surface and artificial forestation slope. c) and d) are an example of difficult cases due to the mixture of scrub forest and young forest and land farm. e) and f) show an example of difficult cases due to the mixture of scrub forest, young forest and land grass field.

It was mostly possible to identify scrub forests, young forests, site preparation after logging, bamboo grass, grass fields and agricultural fields with crops by visual interpretation using aerial photograph stereograms and orthophoto images. However, it was sometimes difficult to distinguish these ground objects using HRV-P images due to their similar textures or unclear shapes. As an extreme example, it was hard to identify forests and ponds using HRV-P images (Fig. 4, Table 3). Blocky patterns like tree crowns appeared in the HRV-P images when the contrast was enhanced. This feature seemed to make the brightness of water surfaces and fields covered with vegetation similar to that of forest (Fig. 4). If these vegetation types coexist with forests in small areas in mountains, distinguishing them from forests is difficult. These 
Table 3 Possibility of ARD detection by visual interpretation

\begin{tabular}{|c|c|c|c|c|}
\hline & \multirow[b]{2}{*}{$\mathrm{ARD}$ interpreting case } & \multicolumn{3}{|c|}{ Possibility of interpretation by image differences } \\
\hline & & $\begin{array}{l}\text { Ortho photos } \\
\text { (spatial resolu- } \\
\text { tion } 1 \mathrm{~m} \text { ) }\end{array}$ & $\begin{array}{l}\text { SPOT ortho } \\
\text { (spatial resolu- } \\
\text { tion } 2.5 \mathrm{~m} \text { ) }\end{array}$ & $\begin{array}{l}\text { Aerial photograph } \\
\text { stereogram (about } \\
\text { map scale } 1 \\
\text { to } 16000 \text { ) }\end{array}$ \\
\hline \multirow{6}{*}{$\begin{array}{l}\text { Interpretation error due } \\
\text { to HRV-P image quality }\end{array}$} & Scrub forest*, young forest and grass field or farm land & $\mathrm{O}$ & $\triangle$ & 0 \\
\hline & $\begin{array}{l}\text { Scrub forest, young forest and replanted cut slope or grass } \\
\text { field }\end{array}$ & $\triangle$ & $\times$ & 0 \\
\hline & Similar brightness to forest, such as pond and forest & 0 & $\triangle$ & 0 \\
\hline & Logging area and grass field (furrow, bench) & 0 & $\triangle$ & 0 \\
\hline & Forest and bamboo grass & $\bigcirc$ & $\triangle$ & 0 \\
\hline & $\begin{array}{l}\text { Coniferous forest, such as Japanese cedar and tea } \\
\text { garden or orchid }\end{array}$ & $\bigcirc$ & $\triangle$ & O \\
\hline \multirow{2}{*}{$\begin{array}{l}\text { Difficult cases in interpret- } \\
\text { ing land-use and cover } \\
\text { regardless of image quality }\end{array}$} & $\begin{array}{l}\text { Fuelwood forest like sawtooth oak and orchards such as } \\
\text { chestnut, persimmon, tea gardens }\end{array}$ & $\triangle$ & $x$ & $\triangle$ \\
\hline & Forest and afforestation garden (land farm) & $x$ & $\times$ & $\times$ \\
\hline \multirow{2}{*}{$\begin{array}{l}\text { Interpretable change } \\
\text { beyond image quality }\end{array}$} & $\begin{array}{l}\text { Large land development, such as quarries and residential } \\
\text { districts }\end{array}$ & O & O & $\bigcirc$ \\
\hline & road (forest road) development (more than $3 \mathrm{~m}$ in width) & 0 & 0 & $\mathrm{O}$ \\
\hline
\end{tabular}

: accurately interpretable

$\triangle$ : sometimes not interpretable due to peripheral circumstance

$x$ : not accurately interpretable

*The definition of scrub forest is qualitative and it means that the tree crown is obscure in the visual interpretation. Thus, coniferous afforestation areas after complete site preparation are excluded since their canopies are identified clearly.

Table 4 Factors of error generation by visual interpretation using HRV-P image

\begin{tabular}{lcl}
\hline \multicolumn{1}{c}{ Reason } & Rate within errors & \multicolumn{1}{c}{ Causality } \\
\hline Error mainly due to HRV-P image quality & $21 \%$ & $\begin{array}{l}\text { Mistake grass field in the mountains and slopes in developing areas for } \\
\text { forest. }\end{array}$ \\
\hline Oversight of land-cover change & $20 \%$ & Visual oversight of land-cover changed area. \\
\hline Time difference & $17 \%$ & Time difference between two images at EP. \\
\hline Registration error & $40 \%$ & $\begin{array}{l}\text { Registration error of EP HRV-P and EP orthophoto images cause } \\
\text { differences in ARD boundary digitization. }\end{array}$ \\
\hline False interpretation & $2 \%$ & False interpretation of land-use in the beginning of period ortho image. \\
\hline
\end{tabular}

${ }^{*}$ All changes were integrated into land-cover change to evaluate. EP: end of the period.

errors were caused by the poorer quality of the HRV-P images.

Comparison of Interpretation Results between Orthophoto and HRV-P Images

As described above, the orthophoto images were superior in distinguishing forest from non-forest areas accurately, and we evaluated differences in visual interpretation using the orthophoto or HRV-P images as the EP images. We assumed that the interpretation results using the orthophoto images were true. We converted the interpreted ARD polygons to $30 \mathrm{~m}$ cells, and checked difference of interpreted ARD between using the orthophoto images and the HRV-P images (Fig. 5). The results showed that the producer's accuracy, which refers to how accurately the interpreted results obtained with the EP HRV-P images agree with the results obtained with the EP orthophoto images, was $82.7 \%$ for interpreted changes from forest to non-forest and $72.5 \%$ for changes from non-forest to forest. User's Accuracy, which refers to how accurately the interpreted results obtained with the EP orthophoto images agreed with the results obtained with the EP HRV-P images, was $80.0 \%$ in the case of the change from non-forest to forest, and $71.1 \%$ from forest to non-forest. Kappa coefficient was 0.771 . Thus, there was about a $20-30 \%$ difference in the interpretation results between using the EP orthophoto images and the EP HRV-P image.

Field validations showed the causes of the discrepancy in the visual interpretation (Table 4). The error due to misinterpretation between forests and grass fields or farm land appeared to be $21 \%$ of the total. Such misinterpretation arose due to the lack of quality or resolution in the HRV-P images compared with the orthophoto images as described previously. 


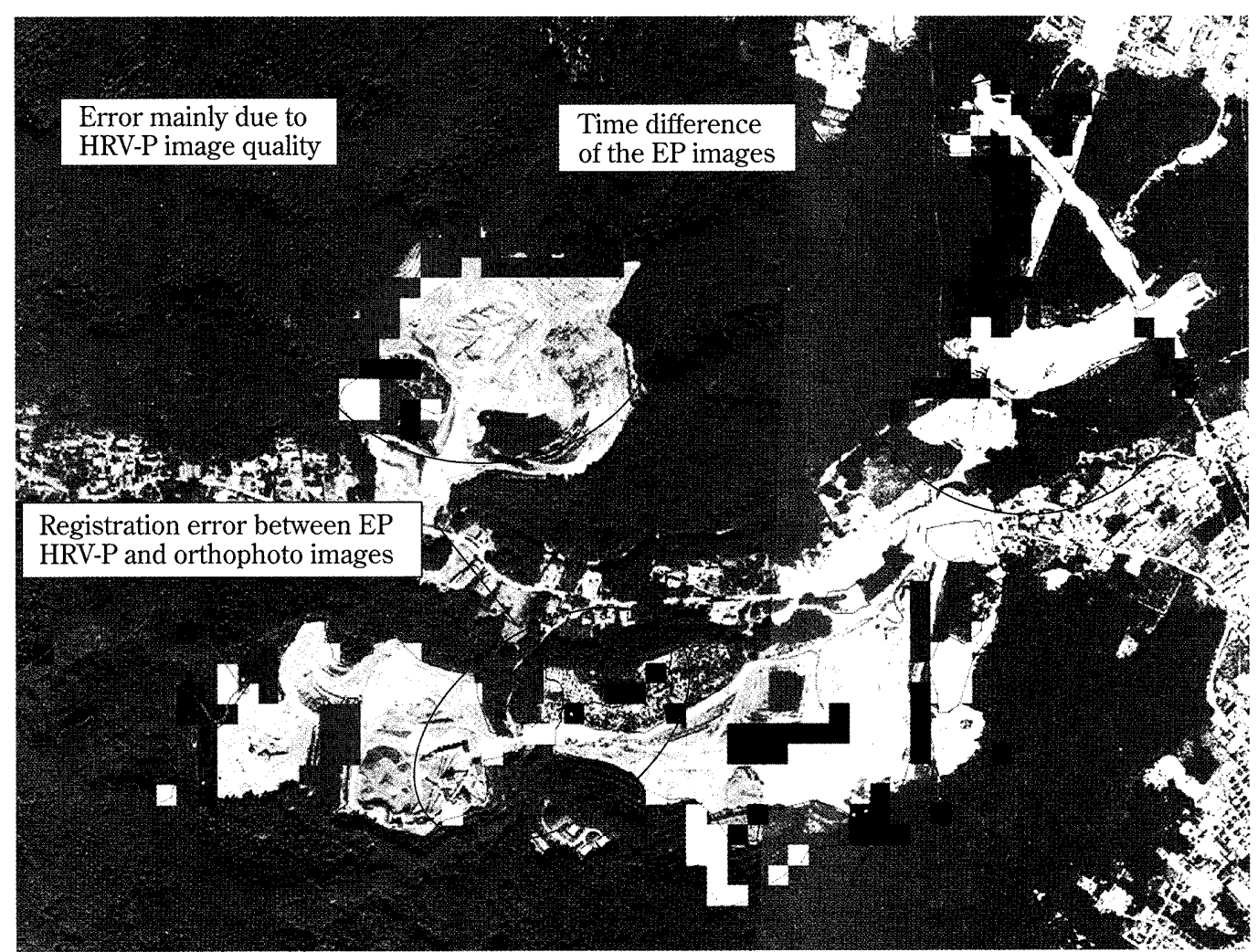

The background image is the EP orthophoto.

\begin{tabular}{|c|c|c|c|c|c|c|}
\hline \multicolumn{6}{|c|}{ Legend } & \multirow{3}{*}{$\begin{array}{l}\text { Accord- } \\
\text { ance }\end{array}$} \\
\hline \multicolumn{3}{|c|}{ Ortho \& ortho comparison } & \multicolumn{3}{|c|}{ Ortho \& HRV-P comparison } & \\
\hline $\begin{array}{c}\text { At the } \\
\text { beginning }\end{array}$ & At the end & $\begin{array}{c}\text { Change } \\
\text { type }\end{array}$ & $\begin{array}{c}\text { At the } \\
\text { beginning }\end{array}$ & At the end & \begin{tabular}{|c|}
$\begin{array}{c}\text { Change } \\
\text { type }\end{array}$ \\
\end{tabular} & \\
\hline Forest & Non-forest & $\mathrm{D}$ & Forest & Non-forest & $\mathrm{D}$ & Yes \\
\hline Non-forest & Forest & $\mathrm{AR}$ & Non-forest & Forest & $\mathrm{AR}$ & Yes \\
\hline Forest & Non-forest & FMD & Forest & Non-forest & FMD & Yes \\
\hline Non-forest & Forest & FMAR & Non-forest & Forest & FMAR & Yes \\
\hline Non-forest & Non-forest & $\begin{array}{c}\text { No } \\
\text { Change }\end{array}$ & Non-forest & Forest & $\begin{array}{c}\mathrm{AR} \\
\text { FMAR }\end{array}$ & No \\
\hline Forest & Forest & $\begin{array}{c}\text { No } \\
\text { Change }\end{array}$ & Forest & Non-forest & $\begin{array}{c}\mathrm{D} \\
\mathrm{FMD}\end{array}$ & No \\
\hline Non-forest & Forest & $\begin{array}{c}\text { AR } \\
\text { FMAR }\end{array}$ & Non-forest & Non-forest & $\begin{array}{c}\text { No } \\
\text { Change }\end{array}$ & No \\
\hline Forest & Non-forest & $\begin{array}{c}\mathrm{D} \\
\text { FMD }\end{array}$ & Forest & Forest & \begin{tabular}{|c|} 
No \\
Change
\end{tabular} & No \\
\hline Non-forest & Forest & $\begin{array}{c}\text { AR } \\
\text { FMAR }\end{array}$ & Forest & Non-forest & $\begin{array}{c}\mathrm{D} \\
\mathrm{FMD}\end{array}$ & No \\
\hline
\end{tabular}

Fig. 5 Example of the difference between interpretation results The background image is the digital orthophoto in 2001. Causes of interpretation mismatching between using the EP orthophoto and the EP HRV-P images are shown in the figure for some areas. 
Vegetated fields such as farm land, grass fields and replanted cut slopes where grass and/or trees were replanted on the face of slopes were misinterpreted as forests in farmlands coexisting with forests in mountainous regions. Thus either distinguishing neighboring land-cover types easily or not seems to change the accuracy of the HRV-P image interpretation. On the other hand, misinterpretation of landuse in the BP images accounted for only $2 \%$ of the total error.

Furthermore, errors due to oversight of changed areas in photo-interpretation occurred at a rate of more than $20 \%$ (Table 4). Misinterpretation and oversight are the major causes of the accuracy decrease in photo-interpretation.

Registration errors between the two types of EP images reached $40 \%$ of errors (Table 4 ) and caused slight differences along the interpreted polygon boundaries which were shown by the open enclosed areas (Fig. 5). Registration errors are critical in distinguishing small changes. Although $17 \%$ of the errors were caused by the difference of the observation dates between both of the EP images, the time difference is not an interpretation error but a problem in evaluation.

To reduce interpretation uncertainties and errors caused by the HRV-P image quality, it is important to judge forests in the HRV-P images by the land-cover texture by referring to the corresponding $\mathrm{BP}$ orthophoto images and the neighboring land-use situation. It is also important to improve the photointerpretation method so as to decrease oversight of the changed areas caused by misinterpretation of brightness changes.

ARD Detection on a Prefecture Scale

After the test interpretation in Hachioji, we conducted an ARD interpretation according to the interpretation types in Table 2 by setting square areas of $2.5 \mathrm{~km} \times 2.5 \mathrm{~km}$, which amounted to $588.9 \mathrm{~km}^{2}$ in total in Kumamoto. The results are shown in Table 5 . The AR area was $0.13 \mathrm{~km}^{2}$ and the D area was $4.5 \mathrm{~km}^{2}$ according to the interpretation results. Annual occurrence rates of AR and D became $0.001 \%$ and $0.048 \%$ of land area, respectively based on the time span of the observation dates between the BP and EP images.

Moreover, we found that land-cover changes from nonforest to forest caused by forestry operations (FMAR) were about 70 times as much as that of AR in land-use. The landcover changes from forest to non-forest caused by forestry operations (FMD) were about three times as much as the change by $\mathrm{D}$ in land-use. The interpretation results revealed that AR occurred very little compared with changes by forestry operations such as tree planting in cutover forests.

We conducted a field check of over 228 sites with unclear causes in the visual interpretation to know the reasons of changes. The number of sites obtaining a perfect match between the interpretation results and field verification was 189 sites (83\%) along the diagonal axis of Table 6, and identifying D in land-use and FMD was difficult. Since the field check was executed only for the results with unclear changes, the interpretation accuracy must be better than $83 \%$.

Table 7 shows a summary of the possible error factors of this visual photo-interpretation method. Twelve patterns of misinterpretation could occur in land-use change interpretation between forest and non-forest. The main problem was the difficulty in interpreting young trees less than 10 years old in $\mathrm{AR}$ areas due to rather coarse ground resolution of the EP HRV-P images compared to the canopy size of young trees. Interpretation errors occurred frequently in the shaded categories in Table 7. Young forests were hard to distinguish from crop fields and grasslands, and caused many errors. Misinterpretation of cut-over areas such as D was another major cause of errors.

On the other hand, it became clearer during this study that the difference in definition which is land-use in the Kyoto

Table $5 \mathrm{ARD}$ area according to the interpreted results in Kumamoto

\begin{tabular}{|c|c|c|c|c|c|}
\hline \multirow{2}{*}{\multicolumn{3}{|c|}{$\begin{array}{l}\text { Effective area (excluding illegible } \\
\text { area such as that under clouds) }\end{array}$}} & Land Area $\left(\mathrm{km}^{2}\right)$ & Areal ratio (\%) & Annual change rate $(\%)^{* 1}$ \\
\hline & & & 588.92 & 100 & - \\
\hline \multirow{4}{*}{$\begin{array}{l}\text { Interpreted } \\
\text { results }\end{array}$} & \multirow{2}{*}{ Land-cover change } & $\begin{array}{l}\text { Non-forest to forest/ } \\
\text { FMAR ARQ }\end{array}$ & 9.59 & 1.63 & 0.102 \\
\hline & & $\begin{array}{l}\text { Forest to non-forest/ } \\
\text { FMD DQ }\end{array}$ & 13.36 & 2.27 & 0.142 \\
\hline & \multirow{2}{*}{ Land-use change } & $\begin{array}{l}\text { Afforestation, } \\
\text { Reforestation/AR }\end{array}$ & 0.13 & 0.02 & 0.001 \\
\hline & & Deforestation/D & 4.5 & 0.76 & 0.048 \\
\hline \multicolumn{3}{|c|}{ Area of Kumamoto prefecture ${ }^{* 2}$} & 6909.30 & 100 & - \\
\hline $\begin{array}{l}\text { The World } \\
\text { and Forestry }\end{array}$ & $\begin{array}{l}\text { Census of Agriculture } \\
2000 \text { (MAFFSSD, 2000) }\end{array}$ & $\begin{array}{l}\text { The area converted from } \\
\text { forests into other land-uses } \\
(1990.4 .1 \sim 2000.3 .31)\end{array}$ & 22.14 & 0.32 & 0.032 \\
\hline
\end{tabular}

${ }^{* 1}$ Annual change rate was a mean value of the interpreted area per year during 16 years between the average acquisition date of photos in the beginning of period and 2004, the year of HRV-P image acquisition.

${ }^{* 2}$ Cited from nationwide square investigation by Geographical Survey Institute in 2004 
Table 6 Summary of field verification of the interpreted results in Kumamoto

\begin{tabular}{|c|c|c|c|c|c|c|c|}
\hline & & \multicolumn{6}{|c|}{ Interpreted results } \\
\hline & & $\mathrm{AR}$ & FMAR & $\mathrm{ARQ}$ & $\mathrm{D}$ & FMD & $\mathrm{DQ}$ \\
\hline \multirow{8}{*}{$\begin{array}{l}\text { The } \\
\text { results } \\
\text { of field } \\
\text { verifi- } \\
\text { cation }\end{array}$} & $\mathrm{AR}$ & 4 & & & & & \\
\hline & FMAR & & 17 & & & & \\
\hline & ARQ & & & 3 & & & \\
\hline & $\mathrm{D}$ & & & & 123 & 15 & \\
\hline & FMD & & & & 5 & 42 & 1 \\
\hline & $\mathrm{DQ}$ & & & & & & \\
\hline & Interpreting non-changing area for changing area ${ }^{* 1}$ & 1 & 2 & & 4 & 5 & \\
\hline & Others ${ }^{* 2}$ & 3 & & & 1 & 2 & \\
\hline \multicolumn{2}{|c|}{ The sum of field verification } & 8 & 19 & 3 & 133 & 64 & 1 \\
\hline \multicolumn{2}{|c|}{ Concordance rate with interpreting results } & $50 \%$ & $89 \%$ & $100 \%$ & $92 \%$ & $66 \%$ & $0 \%$ \\
\hline
\end{tabular}

Accordance with interpreting results

$189 /$ Total field verification $228=83 \%$

${ }^{* 1}$ We define the change from coniferous tree to bamboo grove as cut-over. We also define orchid as forest and green of park as forestation of tree farm.

${ }^{* 2}$ The results of field verification are unclear about cut-over land as to whether it is for land-use change or for forestry.

Table 7 Error factor of interpretation method

\begin{tabular}{|c|c|c|c|c|c|c|}
\hline \multicolumn{3}{|c|}{ Land-use } & \multicolumn{3}{|c|}{ Interpretation } & \multirow{2}{*}{$\begin{array}{l}\text { Frequency of miss- } \\
\text { interpretation/Example }\end{array}$} \\
\hline $\begin{array}{l}\text { At the } \\
\text { beginning }\end{array}$ & At the end & ARD Land use & $\begin{array}{l}\text { At the } \\
\text { beginning }\end{array}$ & At the end & Detection & \\
\hline Forest & Forest & No change & \begin{tabular}{|l|}
$\begin{array}{l}\text { Non-forest } \\
\text { (error) }\end{array}$ \\
\end{tabular} & $\begin{array}{l}\text { Non-forest } \\
\text { (error) }\end{array}$ & No change & $\begin{array}{l}\text { Frequency : Very low/Non tree } \\
\text { area for non-forest. }\end{array}$ \\
\hline Forest & Forest & No change & $\begin{array}{l}\text { Non-forest } \\
\text { (error) }\end{array}$ & Forest & AR & $\begin{array}{l}\text { Frequency : Low/Forest at the } \\
\text { beginning of period for crop } \\
\text { fields. }\end{array}$ \\
\hline Forest & Forest & No change & Forest & $\begin{array}{l}\text { Non-forest } \\
\text { (error) }\end{array}$ & $\mathrm{D}$ & $\begin{array}{l}\text { Frequency : Middle/Cut-over } \\
\text { areas are interpreted as } \\
\text { Deforestation. }\end{array}$ \\
\hline Non-forest & Non-forest & No change & Forest (error) & Forest (error) & No change & $\begin{array}{l}\text { Frequency : Very low/Grass } \\
\text { lands, land under perennial crops } \\
\text { (crop fields) for forest. }\end{array}$ \\
\hline Non-forest & Non-forest & No change & Forest (error) & Non-forest & D & $\begin{array}{l}\text { Frequency : Low/Crop fields for } \\
\text { forest. }\end{array}$ \\
\hline Non-forest & Non-forest & No change & Non-forest & Forest (error) & $\mathrm{AR}$ & $\begin{array}{l}\text { Frequency : Middle/Crop fields or } \\
\text { grass lands are interpreted as } \\
\text { forest at the end. }\end{array}$ \\
\hline Forest & Non-forest & $\mathrm{D}$ & $\begin{array}{l}\text { Non-forest } \\
\text { (error) }\end{array}$ & Forest (error) & AR & $\begin{array}{l}\text { Frequency : Very low/Cut-over } \\
\text { areas at the beginning of period } \\
\text { for non-forest and the end of } \\
\text { period for crop fields. }\end{array}$ \\
\hline Forest & Non-forest & $\mathrm{D}$ & $\begin{array}{l}\text { Non-forest } \\
\text { (error) }\end{array}$ & Non-forest & No change & $\begin{array}{l}\text { Frequency: Low/Cut-over land } \\
\text { for non-forest. }\end{array}$ \\
\hline Forest & Non-forest & $\mathrm{D}$ & Forest & Forest (error) & No change & $\begin{array}{l}\text { Frequency : Middle/Crop field } \\
\text { and grass lands are interpreted } \\
\text { as forest in mountain areas. }\end{array}$ \\
\hline Non-forest & Forest & $\mathrm{AR}$ & Forest (error) & $\begin{array}{l}\text { Non-forest } \\
\text { (error) }\end{array}$ & $\mathrm{D}$ & $\begin{array}{l}\text { Frequency: Very low/Forest at } \\
\text { the beginning of period for grass } \\
\text { lands and forest for grass lands } \\
\text { at the end. }\end{array}$ \\
\hline Non-forest & Forest & $\mathrm{AR}$ & Forest (error) & Forest & No change & $\begin{array}{l}\text { Frequency : Low } / \text { Grass field at } \\
\text { the beginning period for forest. }\end{array}$ \\
\hline Non-forest & Forest & $\mathrm{AR}$ & Non-forest & $\begin{array}{l}\text { Non-forest } \\
\text { (error) }\end{array}$ & No change & $\begin{array}{l}\text { Frequency : Moderate- } \\
\text { high/Difficult recognition of } \\
\text { forest about } 10 \text { years old in the } \\
\text { end of period image. }\end{array}$ \\
\hline
\end{tabular}

Miss interpretations were likely to occur in the shaded categories. 
Protocol and land-cover in image interpretation causes inevitable errors (Table 3). Fuelwood forests and orchards were hard to distinguish by visual interpretation, since trees grow in both land-uses. Forests and gardens with trees were another case of misinterpretation.

Comparison with Administrative Information Regarding LandUse Change

Since no administrative information of AR was available, only the occurrence of $\mathrm{D}$ was compared between the interpretation results and administrative information in
Kumamoto. Square measure of conversion from forest to nonforest land-use is detailed in the World Census of Agriculture and Forestry 2000 (MAFFSSD, 2000) as information about D. That of Kumamoto between 1990 and 2000 amounted to 22.14 $\mathrm{km}^{2}$ (Table 5), and the annual conversion rate was $0.032 \%$ of land area assuming that information about $\mathrm{D}$ in the World Census was equal to the definition by the Kyoto Protocol Article 3.3. The annual $\mathrm{D}$ generation rate according to the interpretation results was $0.048 \%$ of land area (Table 5). Thus the $\mathrm{D}$ generated area from the administrative information was lower by about $23 \%$ than that obtained from the interpretation results. Since producer's and user's accuracies of detecting D

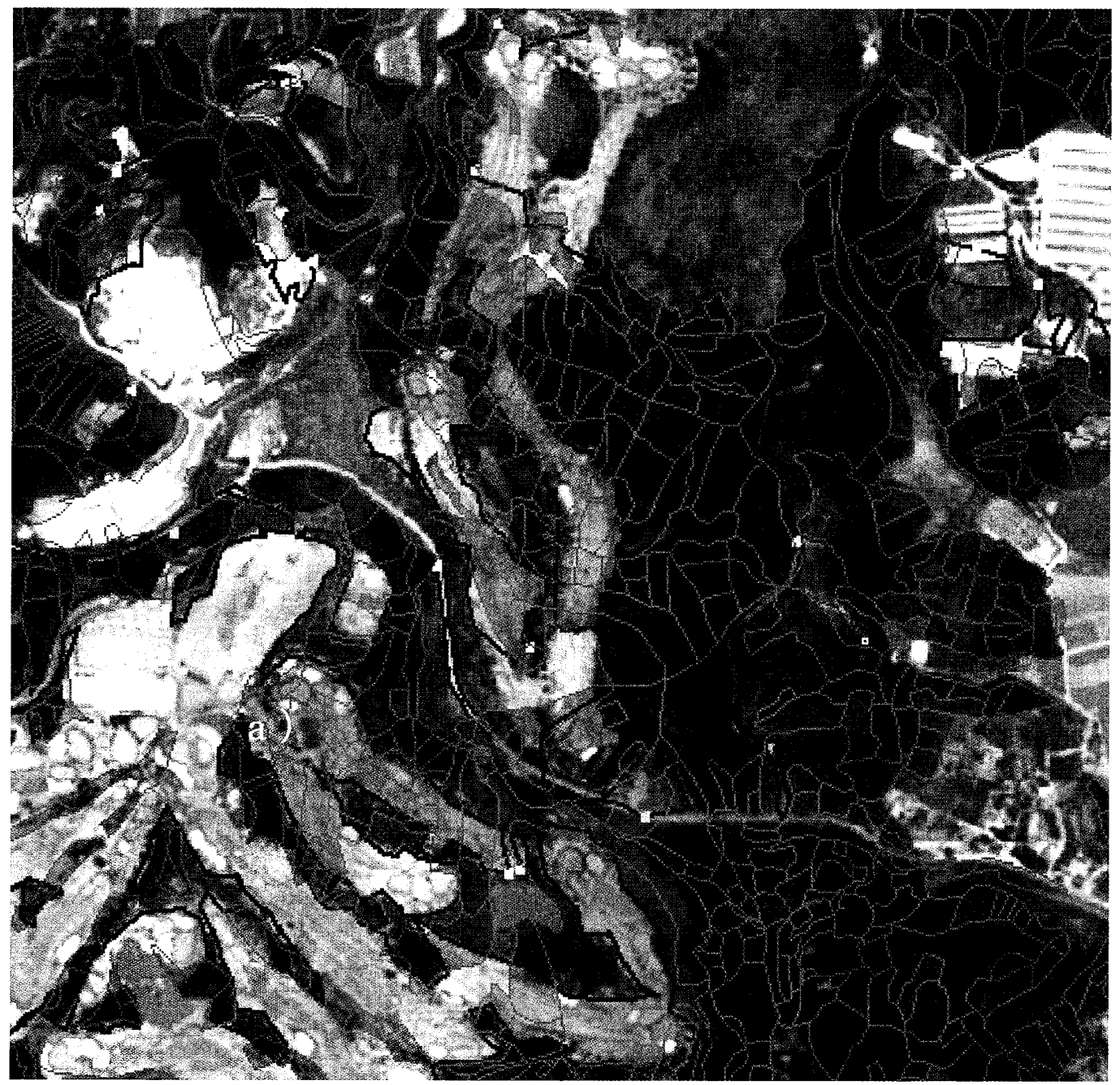

Fig. 6 Comparison between administrative information and interpretation results The EP HRV-P image is superimposed on the private forest area. Heavy red lines $(\square)$ shows deforestation area by interpretation. Thin purple lines $(\square)$ are sub-compartments in 2004 and show private forest areas regulated by the Forest Law article 5 . Areas within private forests are shown in dim blue and others are non-managed forests. The area shown by a) is a deforestation area, although the area is located within the private forest regulated by the Forest Law. 
were $89 \%$ and $92 \%$ respectively based on the field verification results in Table 6, D areas were interpreted accurately. Therefore comparison of administrative information and interpretation results would be important as a cross check of D occurrence by different methods to know how reliable they are.

If sub-compartment boundaries of managed forest at EP are accurate for the Kyoto Protocol Report, we would use the boundary information for ARD detection. However, there are a few reasons to make $A R D$ detection worse, even if the geometric accuracy of polygons is perfect. If the photo interpretation results are displayed on the sub-compartment boundaries, AR or D areas should appear within or without the forest planning area where land was ruled by Forest Law article 5 and 7.2, respectively. If logging areas are located within forest planning areas, the areas should not be D areas. This suggests that sub-compartment boundaries can be used to identify land-use changes accurately as a filter. However this is not always true. Forest sub-compartments in 2003 over forests ruled by the Forest Law article 5 were displayed on a part of interpretation results (Fig. 6). Fig. 6 shows a D area by development of golf links or industrial estates within the forest planning area. Possible reasons of this discrepancy are the time difference of the conversion information about development permission of the forest planning area, transcription errors in the forest planning maps and no change in forest planning maps of deforestation areas under 1ha, which are allowed without development permission.

Moreover, it is not adequate to interpret logging as deforestation by land-use change out of forest planning areas, because forests other than managed forests or trees in orchards may be logged and interpreted as D.

Thus uncertainties arise when administrative information is compared to the interpretation results. Reasons of the uncertainties are summarized as follows, 1) errors in both or either photo interpretation results and administrative information, 2) difference of field state due to difference of obtaining date of data, 3) time lag of reflecting land-use change report to administrative information, and 4) difference of information type, land-use for administrative information and land-cover for remote sensing images.

Improvement for Kyoto Protocol Report

The results of this study are summarized as follows and we have to overcome, reduce or avoid these problems to make accurate ARD detection for the Kyoto Protocol Report.

1) Although reporting land-use changes is required by the Kyoto Protocol, images show land-covers. However, most of land-use changes especially D areas are identifiable (Table 6).

2) There is time difference between the period defined by the Kyoto Protocol and images obtained, or among images obtained (Table 1).

3) Due to poor quality of the EP HRV-P images, misinterpretation of land-covers and land-cover changes arises (Fig. 4, Table 3, 4). However, D would be distinguished accurately (Table 6).

4) Geometric errors in images cause apparent land-cover changes, therefore interpretation errors occur (Fig. 5).

5) Administrative information may be useful for $\mathrm{ARD}$ detection, though we have to pay attention on any errors caused by the reporting system such as time lag between development and reporting or no report of developments under 1 ha.

High spatial resolution ortho-images with high picture quality (e.g. orthophoto images, Table 3) make it easy to detect changes. Above all, many of land-use changes were identifiable due to high spatial resolution which showed ground objects including forest and its surroundings clearly. Cross checks among available ARD information are important to prove the soundness of a report by the Japanese government. Interpreting ARD using ortho-images is worth using in the Kyoto Protocol Report due to its high accuracy especially in detecting $\mathrm{D}$, since reporting $\mathrm{ARD}$ including locations, greenhouse gas emissions by sources and removals by sinks is mandatory (UNITED NATIONS, 1998).

The poor quality of HRV-P images must be overcome by taking into account of surface condition in the BP orthophoto images by interpreters as described previously. To make interpretation easier and more accurate, preparing examples of ARD areas which are hard to distinguish correctly is helpful for interpreters. Interpretation training to interpreters is also helpful to improve accuracy of ARD detection. Furthermore, development of interpretation software, which makes intensity changes between BP and EP images clear by e.g. alarming, is helpful to decrease overlooking changes and to make the photo-interpretation more efficient.

Registration errors due to poor geometric accuracy of EP HRV-P images can be reduced by shifting the HRV-P images to the $\mathrm{BP}$ orthophoto images as described previously. Thus problems in ARD detection by visual interpretation can be reduced, and the ARD detection accuracy seems to be high even without any other supplementary information.

However, undertaking a nationwide ARD photo-interpretation will involve an immense amount of time and effort. Therefore, it is more realistic to perform statistically meaningful interpretation with systematic sampling methods. Information on ARD occurrence rate is needed to design a sampling scheme for ARD detection. Since the annual rate of D was quite similar between administrative information and our results, the occurrence rate of $\mathrm{D}$ by interpretation results is reliable. Occurrence of $\mathrm{AR}$ should be judged by our results even the AR detection accuracy is low, since there is no complete information about AR occurrence for all over Japan.

Since carbon emissions by $\mathrm{D}$ are much greater than carbon sinks by $\mathrm{AR}$, estimating $\mathrm{D}$ areas accurately is very important. Under these situations, interpreting land information only at grid points at a $500 \mathrm{~m}$ interval seemed to be most

\section{J. For. Plann. 13:109-123(2007)}


reasonable to keep error rate less than $2 \%$ based on the sampling theory and occurrence of D in Kumamoto. Checking accuracy of interpretation results in the field is mandatory to reduce uncertainties and to prove reliability of ARD report by the Japanese government to reviewers of country reports.

\section{CONCLUSIONS}

True ARD means human-induced land-use change between forest and non-forest (UNFCCC, 2001). Interpreting the digital orthophoto images at the end of 1989 and high resolution images at the end of monitoring period makes it possible to identify the location where human induced ARD is likely to occur. However, things should be done to make the ARD interpretation more accurate.

1) Interpreters have to judge $\mathrm{ARD}$ (land-use changes) among land-cover changes by texture of images and surrounding objects. 2) Due to difference of acquisition dates of images and $\mathrm{BP}$ and $\mathrm{EP}$, total area of ARD must be presumed by taking into account of the difference. 3) Any auxiliary information (e.g. interpretation example) or methods (e.g. alarming areas with great $\mathrm{DN}$ brightness changes between $\mathrm{BP}$ and EP) are necessary to avoid errors caused by poor picture quality of the EP HRV-P images. 4) Geometric errors in images must be avoided to reduce interpretation errors by misregistration of the $\mathrm{BP}$ and $\mathrm{EP}$ images. 5) Administrative information may be useful for ARD detection.

If we do quality control of interpretation and accuracy assessment of interpretation results carefully, ARD detection by visual interpretation of ortho-images is practical and effective for the Kyoto Protocol Report. Above all, visual photo interpretation overcomes the problem of lack of administrative information at BP. To reduce the enormous effort and time, introducing a systematic sampling of interpretation points would be appropriate.

The most critical problem in visual interpretation was poor quality of HRV-P images. Advances in digital imaging sensors, global positioning system (GPS) and inertial measurement units (IMU) make it possible to obtain digital aerial photos and to produce high quality digital orthophotos using the aerial photos and information supplied by GPS and IMU. If picture quality of HRV-P is not sufficient, producing digital orthophotos at EP would be essential.

\section{ACKNOWLEDGEMENTS}

This study was conducted as part of Forestry Agency Program "National program for measuring and estimating GHGs emissions/removals from Forests". The aerial orthophoto images of Hachioji test site in 2001 were provided by Aero Asahi Corporation. We are indebted for the photointerpretation to Mr. Ryoji Hatamura and Ms. Emi Noguchi of the Japan Forest Technology Association (JFTA), and for field verification of the results in the Kumamoto test site to Mr. Kei
Suzuki and Mr. Tomoki Konno of JFTA. We would like to express to them our deepest gratitude.

\section{LITERATURE CITED}

AkiYama, T. and Kawamura, K., (2003): Study of cloud cover ratio of Landsat-5 for the application on agriculture and forestry. Journal of the Japan Society of Photogrammetry and Remote Sensing 42 (3): 29-34. (in Japanese with English abstract)

Awaya, Y., Kojima, T., Tsukada, N., Kinoshita, H., Iehara, T., Matsumoto, M., Furuya, N., Hori, S. and Hayashi, T., (2006): Outline of national digital orthophoto development using aerial photos taken at the end of 1989 by the forest carbon account and utilization system buildup project of the Forestry Agency. The proceedings of the 57th annual meeting of Japan Forest Society (in press) (in Japanese)

Congalton, R.G., (1991): A Review of Assessing the Accuracy of Classifications of Remotely Sensed Data. Remote Sens. Environ., 37: $35-46 \mathrm{pp}$

Forestry Agency Conservation Division, (2005): Approach in protection forest. Forest Maintenance, Forestry Agency, Tokyo, Japan, 58: 11-13pp (in Japanese*)

Hayashi, M., Hori, S., Iehara, T. and Awaya, Y., (2007): Monitoring the target region of the Kyoto Protocol Article 3.3 with LANDSAT/TM data. Journal of Forest Planning, 13: 17-28

IPCC, (2003): Good Practice Guidance for Land Use, Land-Use Change and Forestry. Institute for Global Environmental Strategies (IGES), Hayama, Japan.

Kakuta, S., Mitani, T., Saito, R., Nakazawa, A., Awaya, Y., Matsumoto, M. and HoR, S., (2007): Methodology of detecting $\mathrm{ARD}$ area by remote sensing. Journal of Forest Planning 13: 29-42

MAS, J.F. (1999): Monitoring land-cover changes: a comparison of change detection techniques. Int. J. Remote Sensing 20(1): 139152.

MAFFPDS (Ministry of Agriculture, Forestry and Fisheries Forest Planning Department Supervision), (2005): Indispensable book on forest planning 2004. Ministry of Agriculture, Forestry and Fisheries, Tokyo, Japan, 24pp and 81pp (in Japanese*)

MAFFSSD (Ministry of Agriculture, Forestry and Fisheries Secretariat Statistics Division), (2000): The World Census of Agriculture and Forestry (2000) Forestry synthesis and statistics reports. Ministry of Agriculture, Forestry and Fisheries, Tokyo, Japan, 124pp (in Japanese*)

MLITSTIS (Ministry of LAND, INFRASTRUCTURE and TRANSPorT, Secretariat Technology Investigation Supervision), (2004): Ministry of Land, Infrastructure and Transport public measurement work regulations corporation Japanese Association of Surveyors. Ministry of Land, Infrastructure and Transport, Tokyo, Japan, 35pp (in Japanese*)

Miyasaka, S., Yoneda, E., Syakaue, H., Takejima, K., Horl, S., Iehara, T. and AwAYA, Y., (2007): Accuracy assessment of ARD detection by RS. Journal of Forest Planning 13: 85-93

Rosenqvist, A., Milne, A., Lucus, R., Imhoff, M. and Dobson, C., (2003): A review of remote sensing technology in support of the Kyoto Protocol. Environmental Science and Policy 6: 441-455.

Thuru, K., (2004): Theory and practice 129 pages of digital photogrammetry: Image quality of aerial photograph. Japan 
Association of Surveyors, Tokyo, Japan, 129pp (in Japanese*)

UNFCCC, (2001): The Marrakech Accords and the Marrakech Declaration. In: Proceedings of the Seventh Conference of the Parties (COP7). Marrakech, Morocco, 29 October-9 November 2001, FCCC/CP/2001/5 (Annex, Section A)

United Nations, (1998): Kyoto Protocol to the United Nations framework convention on climate change. Kyoto, 20pp

${ }^{*}$ The English titles are tentative translations from original Japanese titles by the authors of this paper.

(Received 21 August 2006) (Accepted 16 May 2007) 